\title{
Quadruple-Threshold Credit Risk Modeling: Implications for Corporate Financial Risk Management
}

\author{
Chikashi Tsuji* \\ Graduate School of Systems and Information Engineering, University of Tsukuba, 1-1-1 Tennodai, Tsukuba, Ibaraki \\ 305-8573, Japan
}

\begin{abstract}
This paper develops a new modeling technique for credit risk by applying the self-exciting threshold autoregressive (SETAR) model with quadruple thresholds to the credit spread in Japan. Using this technique, we successfully reveal that the credit spread dynamics in Japan are divided into five risk levels (categories) by four threshold values. Our investigations also clarify that the credit spread in Japan is highly persistent when the spread is in the second-lowest credit risk level, and that it moves faster without showing persistent dynamics when it is in the middle- and higher-credit risk levels. Furthermore, the levels of the boundary values that specify the lowest-and highest-credit risk regimes can be interpreted as a type of value-at-risk measure; it is considered to be an extreme case when the spread is in the lowest- or highest-credit risk levels suggested by our model.
\end{abstract}

Key Words: Credit spread, financial risk management, SETAR model, value-at-risk.

\section{INTRODUCTION}

Credit spread is an important risk measure of credit risk in finance and risk management. Representative existing studies on the credit spread such as Collin-Dufresne and Goldstein [1], Collin-Dufresne et al. [2], and Helwege et al. [3] investigated this spread mainly from the viewpoint of its determinants, as we review later.

Credit rating is also an important credit risk measure in risk management, and it supplies us with objective and concrete credit risk categories such as Aaa or Baa. However, unlike the credit rating, we do not have a criterion with which to judge the various credit risk levels from the actual credit spread. In addition, to the author's knowledge, for credit spreads, no previous study has supplied this kind of objective risk criterion from the viewpoint of macro-credit markets.

The primary objective of this paper is, therefore, to suggest a new credit risk modeling technique by applying the quadruple-threshold self-exciting threshold autoregressive (SETAR) model to the credit spread in Japan. Using this new modeling, we estimate five credit risk regimes and four boundary values of the credit spread, and further reveal the characteristics of the credit spread dynamics in each risk level (category) in Japan. This new modeling technique and the examination of the characteristics of the credit spread in Japan are the most innovative feature of this paper, because no previous study has taken this type of approach to credit risk analysis, as we outline below.

In the context of international studies, an increasing number of papers have applied threshold autoregressive (TAR)

\footnotetext{
*Address correspondence to this author at the Graduate School of Systems and Information Engineering, University of Tsukuba, 1-1-1 Tennodai, Tsukuba, Ibaraki 305-8573, Japan; Tel: +81-29-853-2111;

E-mail: mail_sec_low@minos.ocn.ne.jp
}

models to financial data. ${ }^{1}$ Interesting related studies have been conducted by Clements and Smith [7], Gallagher and Taylor [8], Teräsvirta [9], Tiao and Tsay [10], and van Dijk and Franses [11] as we specifically review later. However, to our knowledge, there has been no study that applied this model to the credit spread. Thus, this is the first application of the SETAR model to the credit spread.

Therefore, this study clearly differs from other preceding works because, as we mentioned above, no studies have attempted to model credit spreads by using the multiple threshold autoregressive model as we have. Furthermore, this study is important for the corporate financial risk management field because this study first supplies an objective risk criterion for credit spread levels with which to judge the credit risk levels from the macro-credit viewpoint. This point will contribute to the financial risk management field by providing a useful viewpoint and standard as well as a valuable insight for understanding the macro-credit risk.

The remainder of this paper is organized as follows. Section II provides a literature review, and Section III describes the data used. In Section IV, we explain our quadruplethreshold SETAR model, and Section V presents the empirical results and our interpretations. Finally, Section VI concludes the paper.

\section{LITERATURE REVIEW}

Below, we first review the literature of TAR models, and then review the literature of credit spreads.

First, with regard to TAR models, Clements and Smith [7] compared the forecast values from the AR model and

\footnotetext{
${ }^{1}$ Threshold autoregressive (TAR) models are a class of nonlinear autoregressive models. These models were first introduced by Tong [4-6] and are based on a simple relaxation of standard linear autoregressive models. In particular, the SETAR model is considered to be useful and effective for analyzing nonlinear financial time-series data.
} 
SETAR model using US GNP data. Gallagher and Taylor [8] concluded that the US market log dividend-price ratio is approximated well by an exponential smooth-transition autoregressive (ESTAR)-autoregressive conditional heteroscedasticity (ARCH) model. Teräsvirta [9] applied the logistic smooth-transition autoregressive (LSTAR) model and the ESTAR model to German and Canadian economic data as examples. Tiao and Tsay [10] considered some recent developments in nonlinear time series analysis including the TAR model using US GDP data, and van Dijk and Franses [11] applied the smooth-transition autoregressive (STAR) model in the context of multiple regimes to US GNP growth rates. Brooks and Garrett [12] investigated the dynamics of the UK FTSE 100 stock and stock index futures markets using the SETAR model. McMillan and Speight [13] reconsidered the time series properties of interwar pound-franc and pounddollar exchange rate returns in the context of a smooth transition version of the TAR model. Coakley and Fuertes [14] explored the long-run behavior and short-run dynamics of quarterly UK real interest rates using a TAR framework. Taylor [15] provided an excellent survey of the literature on long-run purchasing power parity and the stability of real exchange rates, together with an explanation of the applications of the smooth-transition autoregressive models, including the LSTAR and the ESTAR models to real exchange rate data.

On the other hand, regarding the related literature on credit spreads, Jarrow et al. [16] provided a Markov model for the term structure of credit risk spreads. Collin-Dufresne et al. [2] investigated the determinants of credit spread changes. Collin-Dufresne and Goldstein [1] proposed a structural model of default with stochastic interest rates that captures the mean-reverting leverage ratios. Longstaff $e t$ al. [17] used the information in credit default swaps (CDS) to investigate the determinants of corporate yield spreads. Helwege et al. [3] investigated the credit spread determinants from the viewpoint of the structural credit risk model. Tsuji [18] also investigated the determinants of the levels and changes of credit spreads. Blanco et al. [19] tested the theoretical equivalence of CDS prices and credit spreads derived by Duffie [20]. Yu [21] examined whether the quality of a firm's information disclosure can affect the term structure of its credit spreads. Hackbarth et al. [22] developed a framework for analyzing the impact of macroeconomic conditions on credit risk and dynamic capital structure choice. Davydenko and Strebulaev [23] investigated whether strategic auctions of borrowers and lenders affect corporate debt value. Covitz and Downing [24] studied the determinants of very short-term credit spreads. Dailami and Hauswald [25] researched the affect of interlocking contracts on credit spread determinants. Jorion and Zhang [26] revealed the credit contagion effect in Collateralized Debt Obligations' spreads. Feldhütter and Lando [27] decomposed the swap spreads using factor models. Cremers et al. [28] studied whether option-implied jump-risk premia can explain the high observed level of credit spreads. Chen et al. [29] researched the relation between the credit spread puzzle and the equity premium puzzle. David [30] investigated the relation between inflation uncertainty, asset valuations, and the credit spread puzzle.

In the above interesting and influential existing studies for credit risk, there was no attempt to model credit spreads using the SETAR model.

\section{DATA}

Using credit spread data in Japan, we construct the variable, CSPD, which is the percentage-base yield spread between the yield of the NIKKEI bond index (longer term) and the 10-year Japanese government bond yield. The 10-year Japanese government bond yield is from the Bank of Japan, and the yield of the NIKKEI bond index is from Nikkei, Inc. The data are monthly, and the sample period spans from January 1980 to May 2006 (see Fig. 1).

\section{QUADRUPLE-THRESHOLD CREDIT SPREAD MODELING}

In this section, we suggest a new credit spread modeling approach. First, Table 1 shows the Schwarz criterion (SC) for each lag order when we apply the following standard

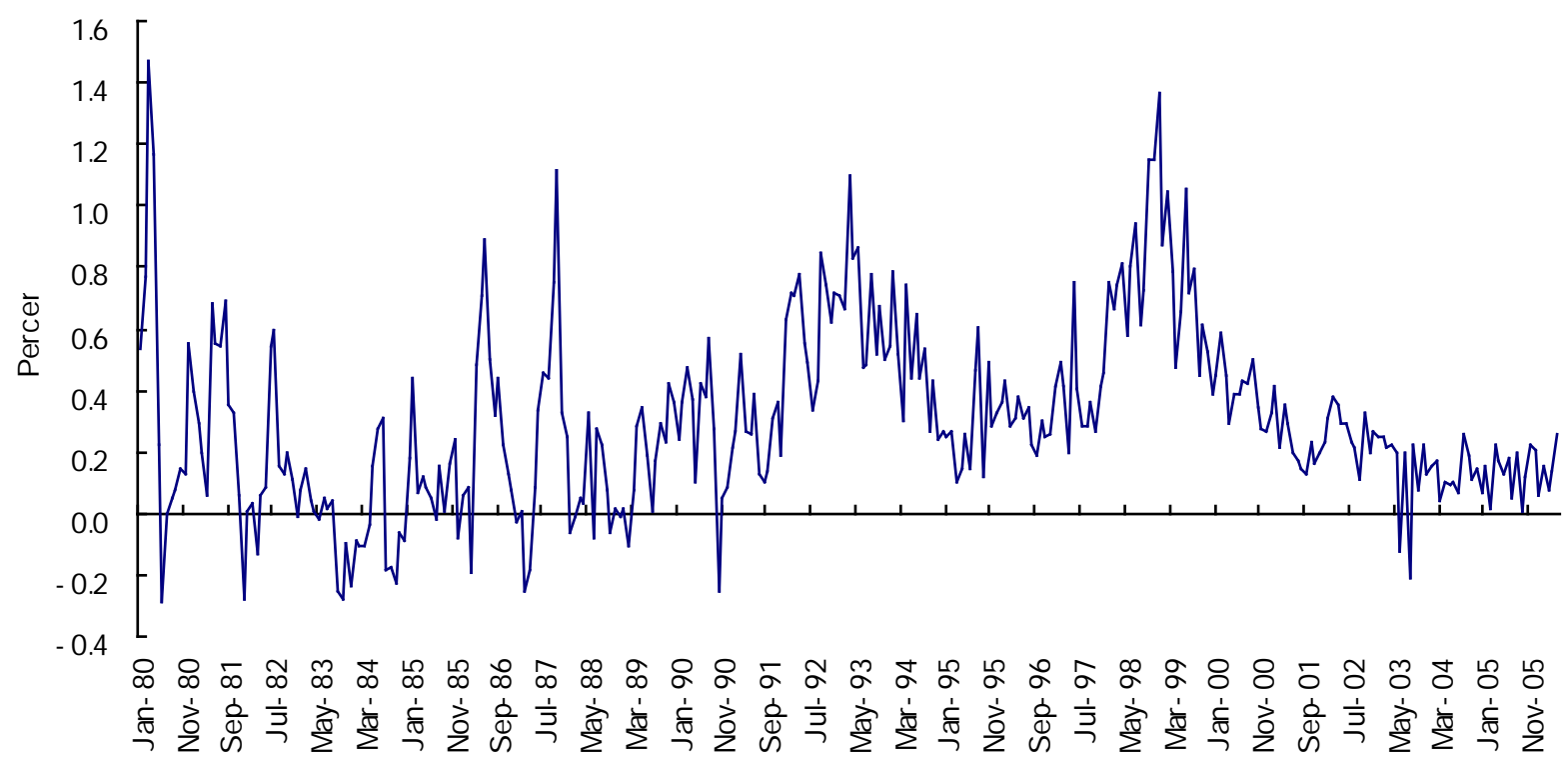

Fig. (1). The dynamics of the credit spread in Japan. 
Table 1. Schwarz Criterion in AR Modeling of the Credit Spread in Japan

\begin{tabular}{|c|c|c|c|c|c|c|c|c|c|c|}
\hline & $\mathbf{A R}(1)$ & $\mathbf{A R}(2)$ & $\mathbf{A R}(3)$ & $\mathbf{A R}(\mathbf{4})$ & $\mathbf{A R}(\mathbf{5})$ & $\mathbf{A R}(\mathbf{6})$ & $\mathbf{A R}(7)$ & $\operatorname{AR}(\mathbf{8})$ & $\operatorname{AR}(\mathbf{9})$ & $\mathbf{A R}(\mathbf{1 0})$ \\
\hline \hline $\mathrm{SC}$ & -0.3824 & -0.3791 & -0.4210 & -0.4014 & -0.4423 & -0.4667 & -0.4590 & -0.4598 & -0.4377 & -0.4166 \\
\hline
\end{tabular}

Notes:

1. Samples are monthly and the sample period is from January 1980 to May 2006

2. SC denotes Schwarz criterion.

3. AR denotes autoregressive terms and the figures in the parenthesis are number of lags.

Table 2. Estimation Results of AR(6) Model in the Credit Spread in Japan

\begin{tabular}{|c|c|c|c|c|c|}
\hline Variable & Coefficient & SE & $\boldsymbol{t}$-Statistic & $\boldsymbol{p}$-Value & Adj. $\boldsymbol{R}^{2}$ \\
\hline \hline Constant & $0.2992^{* * *}$ & 0.0590 & 5.0662 & 0.0000 \\
\hline $\operatorname{AR}(1)$ & $0.5821^{* * *}$ & 0.0581 & 10.0112 & 0.0000 \\
\hline $\operatorname{AR}(2)$ & $0.1709 * * *$ & 0.0626 & 2.7321 & 0.0067 \\
\hline $\operatorname{AR}(3)$ & 0.0438 & 0.0590 & 0.7432 & 0.4579 \\
\hline $\operatorname{AR}(4)$ & -0.0522 & 0.0504 & -1.0374 & 0.3004 & 0.2181 \\
\hline $\operatorname{AR}(5)$ & 0.0728 & 0.0590 & 1.2341 & 0.8121 \\
\hline $\operatorname{AR}(6)$ & 0.0124 & 0.0523 & 0.2379 & 0.8 \\
\hline
\end{tabular}

Notes:

1. Samples are monthly and the sample period is from January 1980 to May 2006

2. SE denotes the standard errors of regressions.

3 . Adj. $R^{2}$ denotes the adjusted $R$-squared value.

4. ***denotes the statistical significance of the coefficients at the $1 \%$ level.

linear $\operatorname{AR}(k)$ model, equation (1), for the credit spread in Japan:

$$
\operatorname{CSPD}_{t}=\gamma_{0}+\sum_{i=1}^{k} \gamma_{i} \operatorname{CSPD}_{t-i}+\varepsilon_{t} .
$$

According to the SC values in Table 1, the appropriate lag length $k$ of model (1) is six, because the SC is minimized when $k=6$. Based on this information, therefore, we estimate an AR(6) model for the credit spread, CSPD, and display the results in Table 2 . Inspecting the statistical significance of the coefficients in the AR(6) model, however, only the constant, $\operatorname{AR}(1)$, and $\operatorname{AR}(2)$ terms are significant. Thus, judging by these simple linear autoregressive relationships, the credit spread in Japan is persistent to the previous two months only.

Therefore, considering this autoregressive relation carefully, we attempt to model the credit spread in Japan by applying the SETAR(1) and SETAR(2) models. ${ }^{2}$ We choose a one-period lag of the credit spread as the state-determining variable following Brooks and Garrett [12]. To be specific, we estimate the following SETAR model, given by equation (2), using the nonlinear least squares (NLS) optimization procedure of Brooks and Garrett [12].

\footnotetext{
${ }^{2}$ We find that unnecessary long lags of the AR terms are an obstacle in specifying the existing multiple regimes in the credit spread dynamics. More concretely, if we take the effects from the long lags into account, we would incorrectly specify the current multiple regimes' situations in the credit spread. Therefore, employing the statistically significant lags of $\operatorname{AR}(1)$ and $\operatorname{AR}(2)$, we remove the noisy lags from $\operatorname{AR}(3)$ to $\operatorname{AR}(6)$.
}

$$
C S P D_{t}= \begin{cases}\gamma_{0,1}+\sum_{i=1}^{k} \gamma_{i, 1} C S P D_{t-i}+\varepsilon_{t, 1} & \text { if } C S P D_{t-1}<r_{0} \\ \gamma_{0,2}+\sum_{i=1}^{k} \gamma_{i, 2} C S P D_{t-i}+\varepsilon_{t, 2} & \text { if } r_{0} \leq C S P D_{t-1}<r_{1} \\ \gamma_{0,3}+\sum_{i=1}^{k} \gamma_{i, 3} C S P D_{t-i}+\varepsilon_{t, 3} & \text { if } r_{1} \leq C S P D_{t-1}<r_{2}, \\ \gamma_{0,4}+\sum_{i=1}^{k} \gamma_{i, 4} C S P D_{t-i}+\varepsilon_{t, 4} & \text { if } r_{2} \leq C S P D_{t-1}<r_{3} \\ \gamma_{0,5}+\sum_{i=1}^{k} \gamma_{i, 5} C S P D_{t-i}+\varepsilon_{t, 5} & \text { if } C S P D_{t-1} \geq r_{3}\end{cases}
$$

where $k=1$ or 2 . In determining the thresholds, we use a grid search procedure, also following Brooks and Garrett $[12] .^{3}$

By modeling the credit spread using this self-excitingquadruple-threshold autoregressive (SE-quadruple-TAR) model, we acquire the four levels of spread values, from $r_{0}$ to $r_{3}$, which specify the boundaries for appropriately dividing all spread dynamics into five credit risk categories or regimes. 4

\footnotetext{
${ }^{3}$ In the grid search procedure, we searched for the threshold value that minimizes the sum of squared residuals, following Brooks and Garrett [12].

${ }^{4}$ Our aim in modeling the credit spread using the SE-quadruple-TAR model in this paper is to appropriately capture the dynamics of the credit spread, and provide a useful criterion for categorizing the credit risk levels through the estimated threshold values. Hence, in this paper, we have no specific proposition for statistical tests of the thresholds. Furthermore, one of the important purposes of our study is to derive implications for corporate financial risk management by modeling the credit spread dynamics using the SETAR model while determining the associated number of regimes. Thus, comparison of the performance of our model with that of other models such as a vector error correction model (VECM) with or without Markov switching, is beyond the scope of this study. We believe that such a variety of models is an opportunity for future research to focus on the technical aspects of these related models. We thank anonymous referees for this point, and will consider this issue in future research.
} 
Table 3. Estimation Results from the Quadruple-Threshold SETAR Model for the Credit Spread in Japan

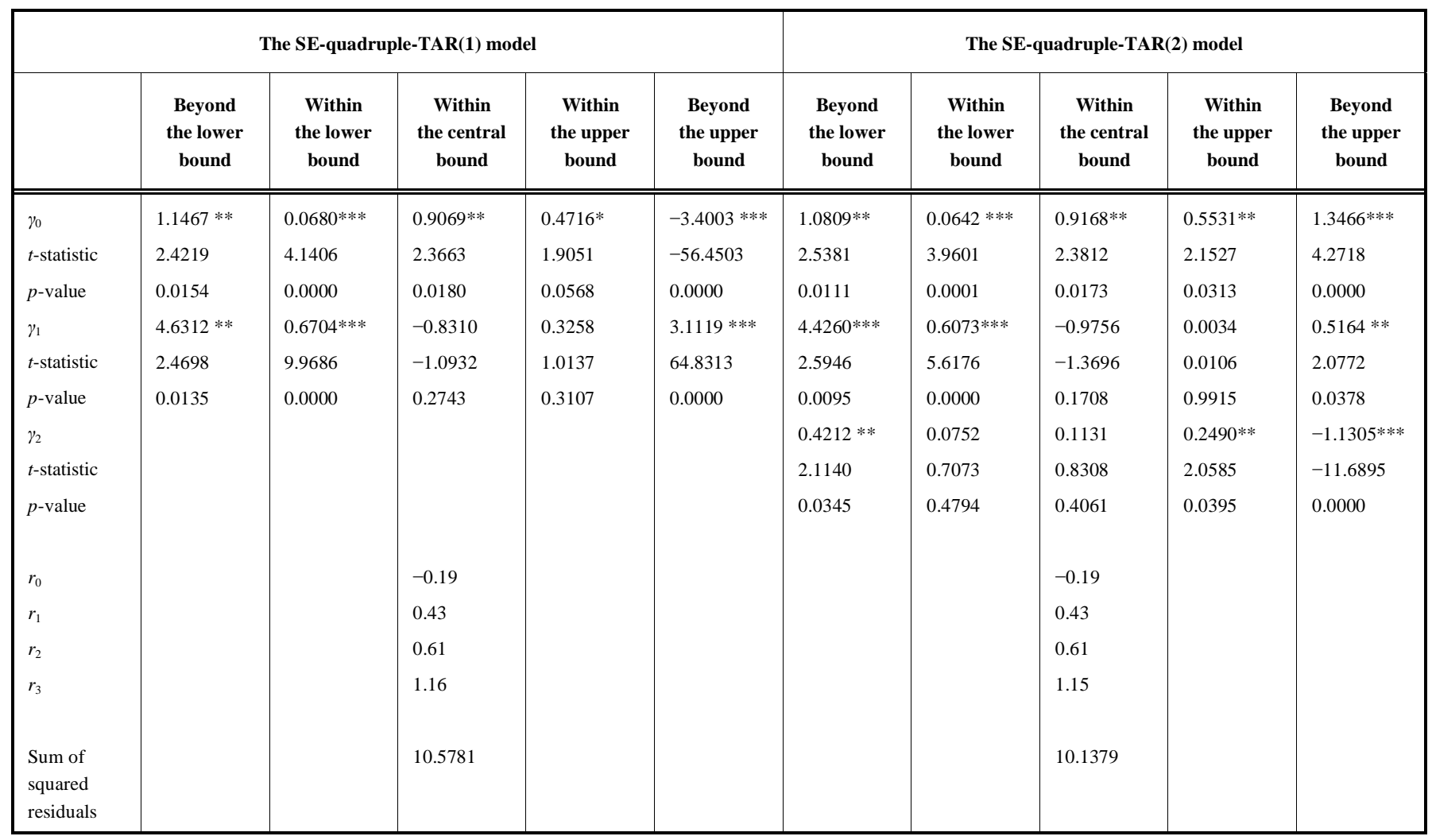

Notes:

1 . *,**, and $* * *$ denote the statistical significance of the coefficients at the $10 \%, 5 \%$, and $1 \%$ levels, respectively.

2. Samples are monthly and the sample period is from January 1980 to May 2006.

3. $\gamma_{0}, \gamma_{1}$, and $\gamma_{2}$ are model parameters, and from $r_{0}$ to $r_{3}$ are the threshold values.

\section{EMPIRICAL RESULTS AND INTERPRETATION}

Results of the estimation of the SE-quadruple-TAR(1) and SE-quadruple-TAR(2) models are shown in Table 3. The results suggest the following. First, the four spread boundary values, derived from the model estimation procedures, were almost the same in the SETAR(1) and SETAR(2) models. Namely, (the percentage-based) credit spread in Japan is divided into five risk categories (regimes or levels) by the quadruple-threshold values of $-0.19 \%, 0.43 \%, 0.61 \%$, and 1.15 or $1.16 \%$. Thus, from these results, we obtain the objective and concrete risk level criterion for the credit market in Japan.

Next, when we denote the above five risk categories as 1) the lowest-credit risk level, 2) the lower-credit risk level, 3) the middle-credit risk level, 4) the higher-credit risk level, and 5) the highest-credit risk level, the credit spread in Japan is the most persistent when the spread is in the lower-credit risk level as the statistically significant $\operatorname{AR}(1)$ term in Table 3 indicates. However, when the spread is in the middle- and higher-credit risk levels, it moves faster to another risk level without showing persistent dynamics, because when the spread is in these two risk categories, there are no statistically significant AR terms (except the AR(2) term in the SETAR(2) model in the higher-credit risk level).

Furthermore, when the spread is in the highest- and lowest-credit risk levels, all AR(1) and AR(2) terms are statistically significant. We suggest that the boundary (threshold) values of the lowest- and highest-credit risk regimes, $-0.19 \%$ and 1.15 or $1.16 \%$, can be considered values of value-at-risk $(\mathrm{VaR})$, which are often used in the area of financial risk management. When we calculate the $1 \%, 5 \%, 95 \%$ and $99 \%$ percentile values using the same samples of the credit spread in Japan, those values are, in order, $-0.254 \%,-0.108 \%$, $0.804 \%$, and $1.153 \%$, respectively. Furthermore, when we calculate the cumulative probabilities of the credit spread distribution using the threshold spread values of $-0.19 \%$ and $1.15 \%$ (or $1.16 \%$ ), they are $2.93 \%$ and $98.87 \%(99.20 \%$ ), respectively. This means that the probabilities of the credit spread in Japan falling into the lowest-credit risk level and the highest-credit risk level are $2.93 \%$ and $1.13 \%$ (or $0.80 \%$ ), respectively. Hence, it is noted that these two boundary values of $r_{0}$ and $r_{3}$ in model (2) can be regarded as values of $\mathrm{VaR}$.

Furthermore, we emphasize here that the credit risk boundary values of $-0.19 \%$ and 1.15 (or $1.16 \%$ ) are implicitly derived from the data itself, and thus it is reasonable to divide the lowest- and highest-credit risk levels by these data-driven threshold values. Percentage values such as $1 \%$, $5 \%$, or $10 \%$, which are often used in calculating the $99 \%$ $\mathrm{VaR}, 95 \% \mathrm{VaR}$, or $90 \% \mathrm{VaR}$, are figures that are artificially determined and are not the figures implied from the actual Japanese credit spread.

Therefore, our derivation of the four threshold values and five regimes from the actual credit spread data, and, in par- 
ticular, our interpretation of the role of the highest and lowest threshold values in our suggested models by relating their values with the values of the traditional risk management model, VaR, are worthwhile contributions of our analysis.

Related to the above, as we mentioned above, the two boundary values of $r_{0}$ and $r_{3}$ in model (2) can be regarded as the VaR values; thus, the highest threshold value and lowest threshold value can be considered to be those values that capture and extract the upward and downward jump risk in the dynamics of the credit spread, respectively. From this viewpoint, setting the highest and lowest threshold values and incorporating a jump component into our model would cause redundancy and conflict, and thus we do not incorporate the jump component into our SE-quadruple-TAR model explicitly. ${ }^{5}$

As above, we believe that our analyses and in-depth interpretations provide valuable insights to understanding the actual dynamics and characteristics of the credit spread in Japan, particularly from the viewpoint of financial risk management.

\section{CONCLUSIONS}

In this paper, we proposed a new modeling method for the credit spread using the SETAR model with five regimes. The new findings from our novel approach are summarized as follows.

- First, the estimation procedure of our SE-quadruple-TAR model supplies the data-driven specific spread boundaries. These four boundary values successfully divided the credit spread dynamics in Japan into five risk levels (regimes), and this approach provided us with objective and concrete multiple credit risk levels for the Japanese credit market.

- Regarding the characteristics of the credit spread dynamics in each regime, the spread is the most persistent when it is in the lower-credit risk level. However, when the spread is in the middle- and higher-credit risk categories, it moves relatively faster to another risk level without showing autoregressive dynamics.

- Furthermore, the boundary values of the lowest- and highest-credit risk regimes can be regarded as values of VaR because empirically derived highest- and lowestcredit risk threshold values from our proposed model correspond to the extreme percentile values in the actual credit spread distribution, and such percentile values are often calculated in the VaR model. That is, we consider it to be an extreme case when the spread is in the lowest or highest risk levels suggested by our model.

Moreover, as our above application to credit risk demonstrates, we suggest that the TAR model and/or the SETAR model are widely applicable in finance. In addition, as the interesting papers by Gallagher and Taylor [8] and Taylor [15] proposed, some smooth-transition autoregressive models are also effective for analyzing real exchange rates. Taylor and Taylor [31] provided many interesting applications of

\footnotetext{
${ }^{5}$ However, interpreting jump risk in the context of our credit risk modeling is quite important considering the recent drastic credit-related crisis caused by subprime lending, and we are grateful to anonymous referees for making this point.
}

these nonlinear models to real exchange rate data. Thus, further research that exploits these nonlinear models in the context of financial markets and risk management from various angles is valuable, not only for Japan, but also for other international financial markets.

\section{ACKNOWLEDGMENTS}

We thank the Japan Society for the Promotion of Science and the Zengin Foundation for Studies on Economics and Finance for their generous financial assistance for this research. We would also like to thank Takao Kobayashi for helpful information on topics related to this paper. We particularly appreciate the very supportive and constructive comments from two anonymous referees of this journal. Finally, we greatly appreciate the invitation of Mehwish Akhter and Sana Zehra to write for this new journal.

\section{REFERENCES}

[1] Collin-Dufresne P, Goldstein RS. Do credit spreads reflect stationary leverage ratios? J Finance 2001; 56: 1929-57.

[2] Collin-Dufresne P, Goldstein RS, Martin JS. The determinants of credit spread changes. J Finance 2001; 56: 2177-207.

[3] Helwege J, Eom YH, Huang J. Structural models of corporate bond pricing: an empirical analysis. Rev Financ Stud 2004; 17: 499-544.

[4] Tong H. On a threshold model. In: Chen CH, Ed. Pattern recognition and signal processing, Sijthoff \& Noordhoff; Amsterdam 1978; pp. 101-41.

[5] Tong H. Threshold Models in Nonlinear Time Series Analysis. New York: Springer-Verlag 1983.

[6] Tong H. Nonlinear Time Series: A Dynamical Systems Approach. Oxford: Oxford University Press 1990.

[7] Clements MP, Smith J. The performance of alternative forecasting methods for SETAR models. Int J Forecasting 1997; 13: 463-75.

[8] Gallagher L, Taylor MP. Risky arbitrage, limits of arbitrage, and nonlinear adjustment in the dividend-price ratio. Econ Inq 2001; 39: 524-36.

[9] Teräsvirta T. Specification, estimation, and evaluation of smooth transition autoregressive models. J Am Stat Assoc 1994; 89: 20818.

[10] Tiao GC, Tsay RS. Some advances in non-linear and adaptive modeling in time-series. J Forecasting 1994; 13: 109-40 (with discussion).

[11] van Dijk D, Franses PH. Modeling multiple regimes in the business cycle. Macroecon Dyn 1999; 3: 311-40.

[12] Brooks C, Garrett I. Can we explain the dynamics of the UK FTSE 100 stock and stock index futures markets? Appl Financ Econ 2002; 12: 25-31.

[13] McMillan DG, Speight AEH. Non-linear dependence in inter-war exchange rates: some further evidence. Appl Econ Lett 2002; 9: 359-64.

[14] Coakley J, Fuertes A. Asymmetric dynamics in UK real interest rates. Appl Financ Econ 2002; 12: 379-87.

[15] Taylor MP. Real exchange rates and Purchasing Power Parity: mean-reversion in economic thought. Appl Financ Econ 2006; 16: $1-17$.

[16] Jarrow RA, Lando D, Turnbull SM. A markov model for the term structure of credit risk spreads. Rev Financ Stud 1997; 10: 481-523.

[17] Longstaff FA, Mithal S, Neis E. Corporate yield spreads: default risk or liquidity? New evidence from the credit default swap market. J Finance 2005; 60: 2213-53.

[18] Tsuji C. The credit-spread puzzle. J Int Money Financ 2005; 24: 1073-89.

[19] Blanco R, Brennan S, Marsh IW. An empirical analysis of the dynamic relation between investment-grade bonds and credit default swaps. J Finance 2005; 60: 2255-81.

[20] Duffie D. Credit swap valuation. Financ Anal J 1999; 55: 73-87.

[21] Yu F. Accounting transparency and the term structure of credit spreads. J Financ Econ 2005; 75: 53-84.

[22] Hackbarth D, Miao J, Morellec E. Capital structure, credit risk, and macroeconomic conditions. J Financ Econ 2006; 82: 519-50. 
[23] Davydenko SA, Strebulaev IA. Strategic actions and credit spreads: an empirical investigation. J Finance 2007; 62: 2633-71.

[24] Covitz D, Downing C. Liquidity or credit risk? The determinants of very short-term corporate yield spreads. J Finance 2007; 62: 230328.

[25] Dailami M, Hauswald R. Credit-spread determinants and interlocking contracts: A study of the Ras Gas project. J Financ Econ 2007; 86: 248-78.

[26] Jorion P, Zhang G. Good and bad credit contagion: Evidence from credit default swaps. J Financ Econ 2007; 84: 860-83.

[27] Feldhütter P, Lando D. Decomposing swap spreads. J Financ Econ 2008; 88: 375-405.
[28] Cremers KJM, Driessen J, Maenhout P. Explaining the level of credit spreads: option-implied jump risk premia in a firm value model. Rev Financ Stud (in press).

[29] Chen L, Collin-Dufresne P, Goldstein RS. On the relation between the credit spread puzzle and the equity premium puzzle. Rev Financ Stud (in press).

[30] David A. Inflation uncertainty, asset valuations, and the credit spreads puzzle. Rev Financ Stud (in press).

[31] Taylor AM, Taylor MP. The purchasing power parity debate. J Econ Perspect 2004; 18: 135-58.

(C) Chikashi Tsuji; Licensee Bentham Open.

This is an open access article licensed under the terms of the Creative Commons Attribution Non-Commercial License (http://creativecommons.org/licenses/ by-nc/3.0/) which permits unrestricted, non-commercial use, distribution and reproduction in any medium, provided the work is properly cited. 